\title{
Effect of Graphene on Modified Asphalt Microstructures Based on Atomic Force Microscopy
}

\author{
Xian Li ${ }^{1}$, Yanmin Wang ${ }^{1, *}$, Yanling Wu ${ }^{1}$, Huiru Wang ${ }^{1}$, Qingliang Wang ${ }^{1}$, Xingxing Zhu ${ }^{1}$, Xiaocun Liu ${ }^{1}$, \\ Huadong Sun ${ }^{1}$ and Liang Fan ${ }^{2}$ (D) \\ 1 School of Traffic and Civil Engineering, Shandong Jiaotong University, Jinan 250300, China; \\ lixian12132021@163.com (X.L.); 204145@sdjtu.edu.cn (Y.W.); whr4159@139.com (H.W.); \\ QL51207@163.com (Q.W.); zhuxing5297@163.com (X.Z.); 204127@sdjtu.edu.cn (X.L.); \\ 204113@sdjtu.edu.cn (H.S.) \\ 2 Shandong Transportation Institute, Jinan 250031, China; fanliang218@sina.com \\ * Correspondence: 212013@sdjtu.edu.cn or ymwangsdu@139.com; Tel.: +86-185-0541-9501
}

check for updates

Citation: Li, X.; Wang, Y.; Wu, Y.; Wang, H.; Wang, Q.; Zhu, X.; Liu, X.; Sun, H.; Fan, L. Effect of Graphene on Modified Asphalt Microstructures Based on Atomic Force Microscopy Materials 2021, 14, 3677. https:// doi.org/10.3390/ma14133677

Academic Editor: Gilda Ferrotti

Received: 23 May 2021

Accepted: 25 June 2021

Published: 1 July 2021

Publisher's Note: MDPI stays neutral with regard to jurisdictional claims in published maps and institutional affiliations.

Copyright: (c) 2021 by the authors. Licensee MDPI, Basel, Switzerland. This article is an open access article distributed under the terms and conditions of the Creative Commons Attribution (CC BY) license (https:// creativecommons.org/licenses/by/ $4.0 /)$.

\begin{abstract}
Atomic force microscopy (AFM) was used to explore the effects of graphene modifier on the microstructure of asphalt. The morphologies of the before- and after-aged base asphalt and modified asphalt were performed and compared with analysis. The formation mechanism of asphaltic "bee structures" and the influence mechanism of graphene on asphalt were discussed from the classical theory of material science (phase transformation theory and diffusion theory). The results show that graphene facilitates the nucleation of "bee structures", resulting in an increasing number and decreasing volume of "bee structures" in modified asphalt. Additionally, the anti-aging performance of the modified asphalt improved significantly because of graphene incorporation.
\end{abstract}

Keywords: AFM; graphene; bee structures; phase transformation theory; anti-aging performance

\section{Introduction}

Asphalt is a complicated mixture of various hydrocarbons and their nonmetallic (oxygen, sulfur, and nitrogen) derivatives. The components of asphalt include alkanes, cycloalkanes, arenes and sulfur-containing derivatives, polycyclic aromatic hydrocarbons, fused polycyclic arenes, and nonmetallic derivatives. Additionally, trace metal elements (vanadium, nickel, magnesium, iron, and calcium) are present in asphalt [1,2]. Although the components and microstructure of asphalt are crucial and affect its pavement performance, microscopic studies pertaining to asphalt are scarce owing to its complex chemical composition and insufficient research resources. In recent years, the relationship among bitumen components, microstructure, and pavement performance has garnered increasing attention. In particular, researchers are focusing on atomic force microscopy (AFM), which is used to investigate the microscopic structure and mechanism of asphalt.

In 1996, Loeber et al. first observed the microstructure of asphalt via AFM, and named the microscopic topography of asphalt as "bee structure." By analyzing the formation process, it was preliminarily discovered that the "bee structure" was due to asphaltene [3]. Pauli et al. demonstrated that the microstructures are primarily due to the interaction between the crystallizing paraffin waxes and the remaining non-wax asphalt components [4]. Similarly, Jäger A. et al. reported that the "bee structure" was due to asphaltene [5]. De Moraes et al. speculated that the property of the "bee structure" is similar to that of microcrystalline wax [6]. Masson et al. investigated the microscopic topographies of 13 types of asphalt and discovered that the formation of "bee structures" was attributed to the content of vanadium and nickel in asphalt [7]. Meanwhile, it was reported that the addition of Trinidad Lake asphalt and SBS modifiers significantly affected the grain size and the distribution of "bee structures" [8,9]. Some researchers reported that the "bee structure" was due to the wrinkling of thin films measuring approximately $10 \mathrm{~nm}$ thick [2,10]. Ji 
et al. used AFM to quantitatively evaluate the microstructure of asphalt via roughness theory [11]. Hung investigated the evolution of the microstructure of asphalt after water exposure [12]. Although achievements as evidenced via AFM have been realized in the microscopic application of asphalt, the formation conditions, mechanism, evolution law, and influencing factors of asphaltic "bee structures" remain inconclusive. Therefore, we try to explore the effect of additives on the microstructure of asphalt and expect to achieve something meaningful.

"Small size effect" nanomaterials naturally have a boundary effect and high specific surface area, which can directly or indirectly lead to a special surface effect. In recent years, nanomaterials used as asphalt modifications have increasingly been studied to improve the mechanical and physical properties of bitumen. Some nanomaterials such as titanium dioxide $\left(\mathrm{TiO}_{2}\right)$ [13], zinc oxide ( $\mathrm{ZnO}$ ) [14], graphene oxide (GO) [15], silicon dioxide $\left(\mathrm{SiO}_{2}\right)$ [16], and montmorillonite [17] have been selected as modifiers to improve the road performance and extend the durability of asphalt. Some very significant results have been achieved. For example, Cheraghian et al. studied the ultraviolet aging resistance of fumed silica nanoparticles modified bitumen and the results show that the anti-ultraviolet aging property of modified asphalt is improved with the increase of nano silica content [18]. Zhang et al. found that the reduction of $\mathrm{ZnO}$ particle size can improve the performance of asphalt binder and asphalt mixture through analyzing the influence of $\mathrm{ZnO}$ particle size on asphalt's physical properties [19].

In our study, graphene was selected as an asphalt modifier. This is mainly because graphene is a novel quasi-two-dimensional (2D) carbon-based nanomaterial with carbon atoms arranged in a honeycomb lattice, and has been investigated as an asphalt modifier owing to its compatibility with asphalt. For example, Wu et al. discovered that incorporating a small amount of graphene oxide (GO) improved the anti-aging property of asphalt [20-22]. Shi et al. investigated the properties and modification mechanism of GO-modified asphalt and discovered that a trace amount of GO restricted the movement of asphalt molecules and improved their high-temperature performance [23-25]. MorenoNavarro et al. discovered that the presence of graphene resulted in a more significant elastic response and reduced the thermal sensitivity of the asphalt binder [26].

Therefore, in this study, the topographies of base A-70 asphalt and graphene-modified asphalt were investigated via AFM. A more comprehensive analysis and discussion would clarify the formation reasons and the effects of graphene on asphaltic "bee structures". Basic material rules, phase transformation theory, and diffusion theory were introduced to interpret the mechanism of graphene on asphalt's microscopic "bee structures."

\section{Experimental}

In this study, A-70 asphalt provided by Shandong Hi-speed Construction Materials, Jinan, China, was used as the base asphalt. Graphene-modified asphalt was home-made and the dosage of graphene was $1 \%$ in weight, which has previously been proven to be the optimal graphene content [27].

\subsection{Preparation of AFM Specimens}

The short- and long-term aging of asphalt were simulated using a rotating film oven heating apparatus (James Cox \& Sons CS325B, Colfax, CA, USA) and a pressure aging apparatus (Prentex PR9300, Sunnyvale, TX, USA), respectively. Unaged, short-term aged, and long-term aged asphalt were prepared separately. AFM specimens were prepared via the heating molding method as follows: First, molten asphalt was deposited onto a glass slide $(10 \mathrm{~mm} \times 10 \mathrm{~mm} \times 1 \mathrm{~mm})$ using a glass rod. Subsequently, the drop was placed in an oven and tilted $30^{\circ}$ above the horizontal. It was heated at $150^{\circ} \mathrm{C}$ for $15 \mathrm{~min}$, and a thin layer of asphalt coated the surface of the slide by gravity. Finally, the glass slide coated with asphalt was cooled to room temperature in the air. The asphalt film prepared via this method measured several microns in thickness, which is similar to the actual thickness of asphalt films on roads [28]. 


\subsection{Atomic Force Microscope Test}

AFM (Bruker Multimode 8, Santa Barbara, CA, USA)was performed to characterize the microstructures of the base and graphene-modified asphalt before and after aging. A schematic diagram of the AFM performed is shown in Figure 1. The four core components used in the AFM were a probe tip, cantilever, laser, and position-sensitive photodiode (PSPD). During scanning, the height variation of the microsurface of the sample will produce a slight force, i.e., an attraction or repulsive force between the probe tip and sample surface. In this case, the cantilever deviates based on "Hooke's Law," resulting in a change in the reflection signal of the laser illuminated on the back of the cantilever. The change in the laser reflection signals can be sensed by the PSPD, and the surface topography of the sample can be obtained after treatment [29]. The topography and phase-contrast images were received in the intermittent contact mode, where the elastic constant of the probe was $0.4 \mathrm{~N} / \mathrm{m}$, scanning rate was $1.5 \mathrm{~Hz}$, scanning area was $10 \mu \mathrm{m} \times 10 \mu \mathrm{m}$, and the resolution was $10 \mathrm{~nm}$.

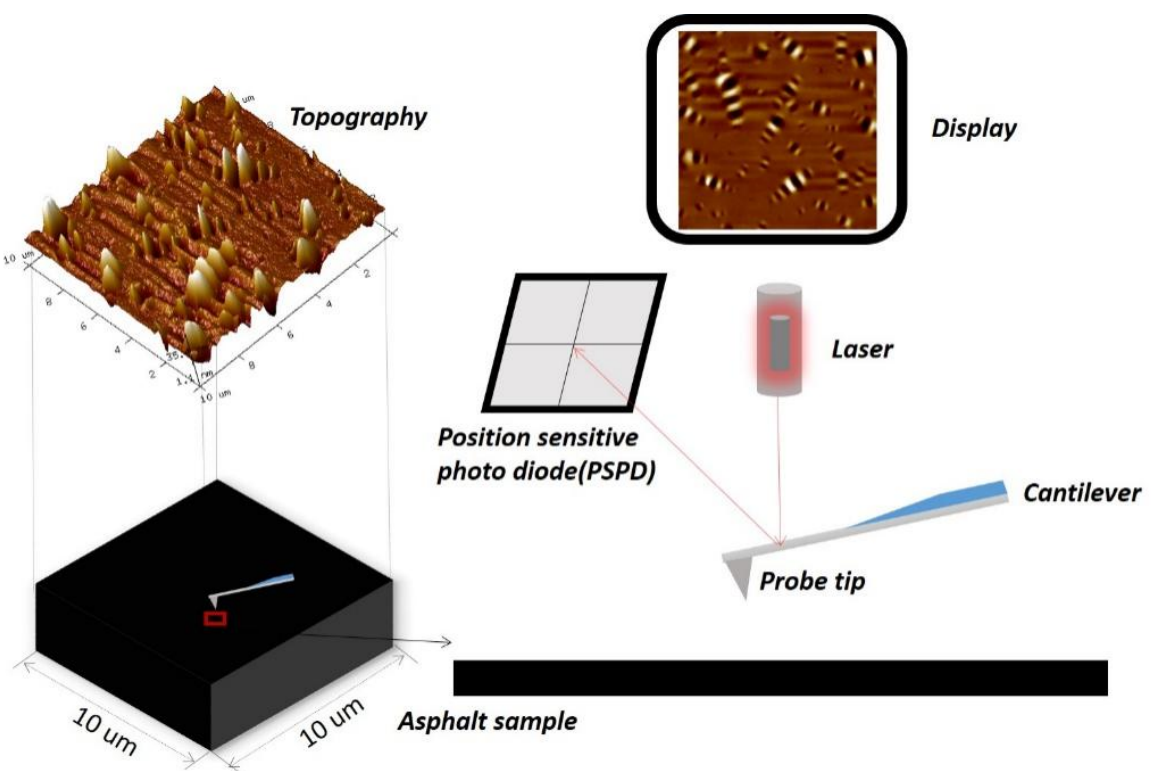

Figure 1. Schematic diagram of AFM.

\section{Results and Discussion}

\subsection{Effect of Graphene on Fundamental Properties of Asphalt}

Figure $2 \mathrm{a}, \mathrm{b}$ show the basic properties of the base and graphene-modified (the dosage of graphene was $1.0 \%$ in weight) asphalt before and after aging, respectively. As shown in Figure 2, both the base and modified asphalt show a trend of decreasing penetration, increasing softening point, increasing viscosity, and decreasing ductility after short-term rolling thin film oven test (RTFOT) aging. The increasing softening point and viscosity indicate that the asphalt becomes hard and brittle after aging. Meanwhile, the anti-aging property of asphalt could also be evaluated by comparing the change rates of the indexes before and after aging. It can be concluded that the changing rate of every index of graphene-modified asphalt was lower than that of the base asphalt. This suggests that the anti-aging performance of the graphene-modified asphalt was superior to that of the base asphalt. Additionally, the high-temperature performance of the modified asphalt improved because of the incorporation of graphene. 


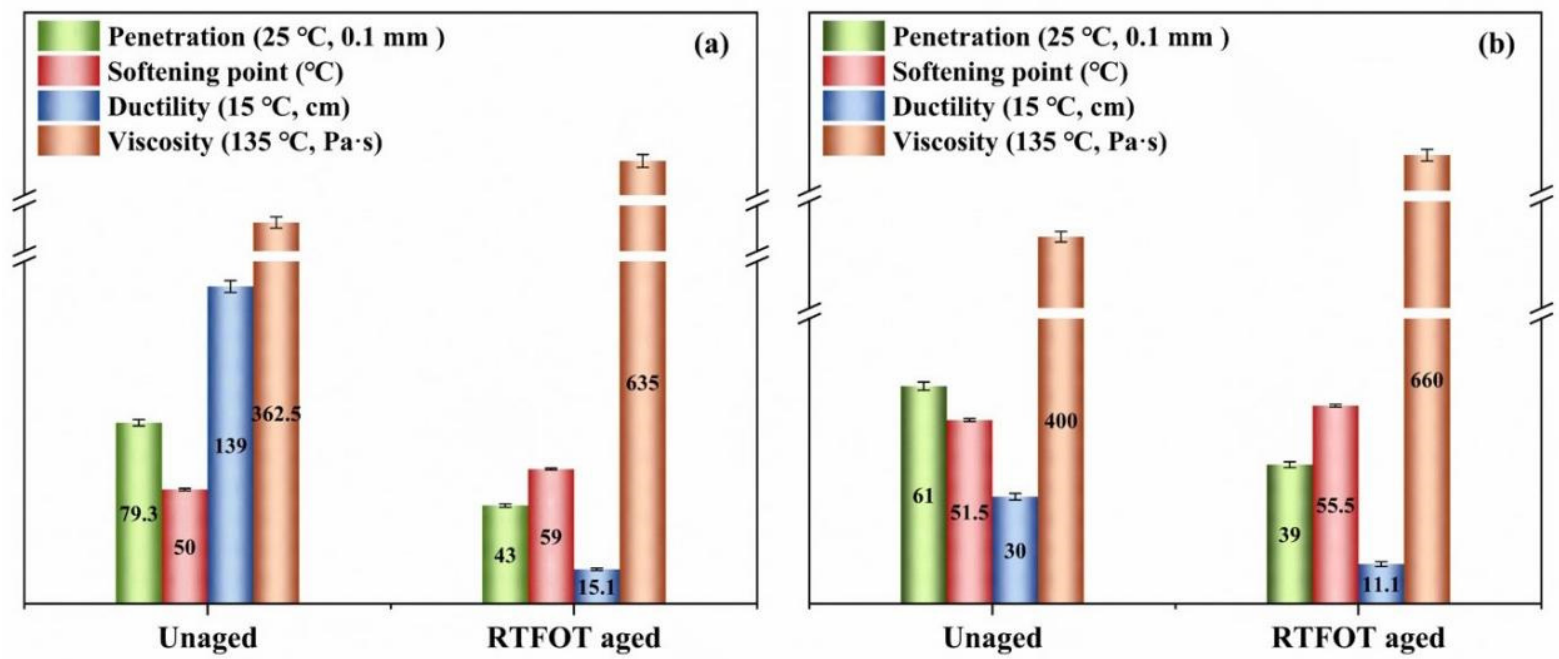

Figure 2. Basic properties of base asphalt (a) and graphene-modified asphalt (b) before and after aging.

\subsection{Effect of Graphene on "Bee Structure"}

Figure 3a,b show the 2D topographies of the base and graphene-modified asphalt measured via AFM, respectively. Three phases (Catana, peri, and para phases) were observed from the images shown in Figure 3. The "bee structure" was composed of interlacing light and dark lines, which represent convex and concave structures, respectively [7,30]. Furthermore, Figure 3a,b show many "bee structures" in the graphene-modified asphalt within the same investigation area. The height of the light, bright peak increased significantly, and the depth of the dark valley decreased, indicating a decrease in the size of the "bee structure" in the graphene-modified asphalt. In other words, in the base asphalt, the "bee structures" are larger but fewer in quantity.

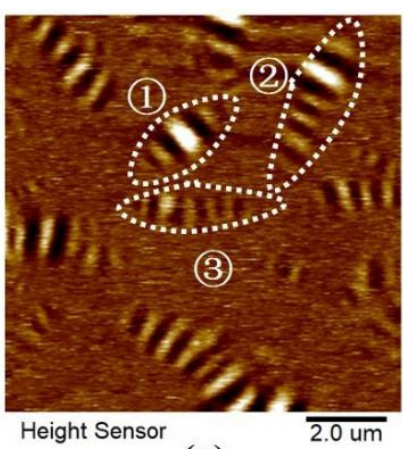

(a)

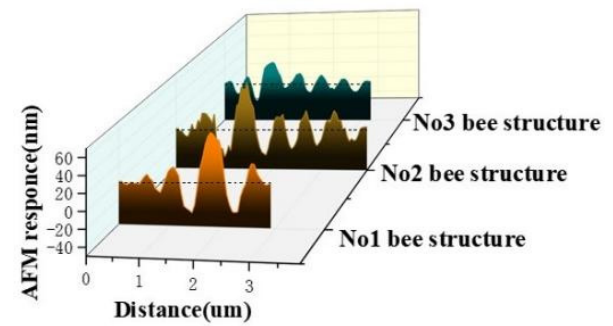

(c)

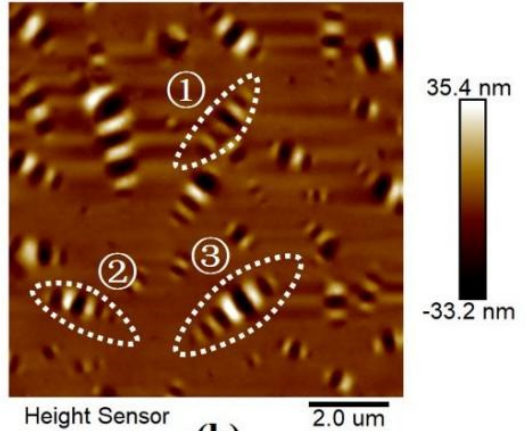

(b)

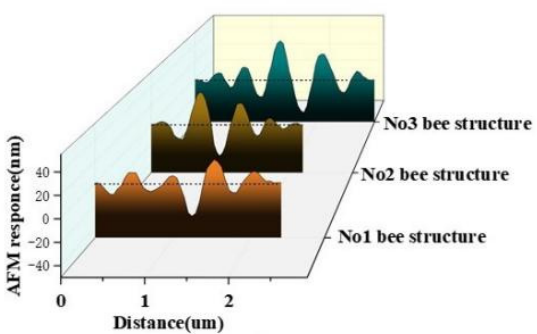

(d)

Figure 3. Topographies of asphalt investigated via AFM. (a) 2D image of base asphalt; (b) 2D image of graphene-modified asphalt; (c) topographic profiles of "bee structures" labeled in (a); (d) topographic profiles of "bee structures" labeled in (b). 
AFM provides topographic information in the form of height lines (or profiles), e.g., the distance between the higher and lower parts of the "bee structure." Figure 3c,d show topographic profiles of the selected representative "bee structures" labeled in Figure $3 \mathrm{a}, \mathrm{b}$, respectively. As shown, the average length of the "bee structure" in the base asphalt was $3-4 \mu \mathrm{m}$, whereas it is reduced to $2-3 \mu \mathrm{m}$ in the graphene-modified asphalt. Additionally, the average altitude of the "bee structure" in base asphalt was approximately $44.2 \mathrm{~nm}$, whereas it was reduced to approximately $35.4 \mathrm{~nm}$ in the graphene-modified asphalt. This reduction shows that the volume of the "bee structure" in asphalt decreased after modification by graphene. By analyzing Figure 3 , it can be speculated that the decline in the "bee structure" volume in the graphene-modified asphalt is primarily related to the factors contributing to the formation of the "bee structures."

\subsection{Effect of Graphene on Microstructure during Asphalt Aging}

Figure 4 shows the three-dimensional (3D) AFM images of the base and graphenemodified asphalt before and after aging. As shown, the surface of the graphene-modified asphalt was smooth, whereas that of the base asphalt was rough. After rolling-thin-filmoven (RTFOT) aging, the variation in the base asphalt surface was more evident than that of the graphene-modified asphalt. Specifically, the peak area increased significantly, and the quantity and size of the "bee structures" increased as well. However, the AFM images of the graphene-modified asphalt before and after aging were similar. The number of "bee structures" in the base and graphene-modified asphalt increased after pressure-aging vessel (PAV) tests. This occurred because the asphalt viscosity increased and the number of large aromatic hydrocarbon molecules increased after aging [31].
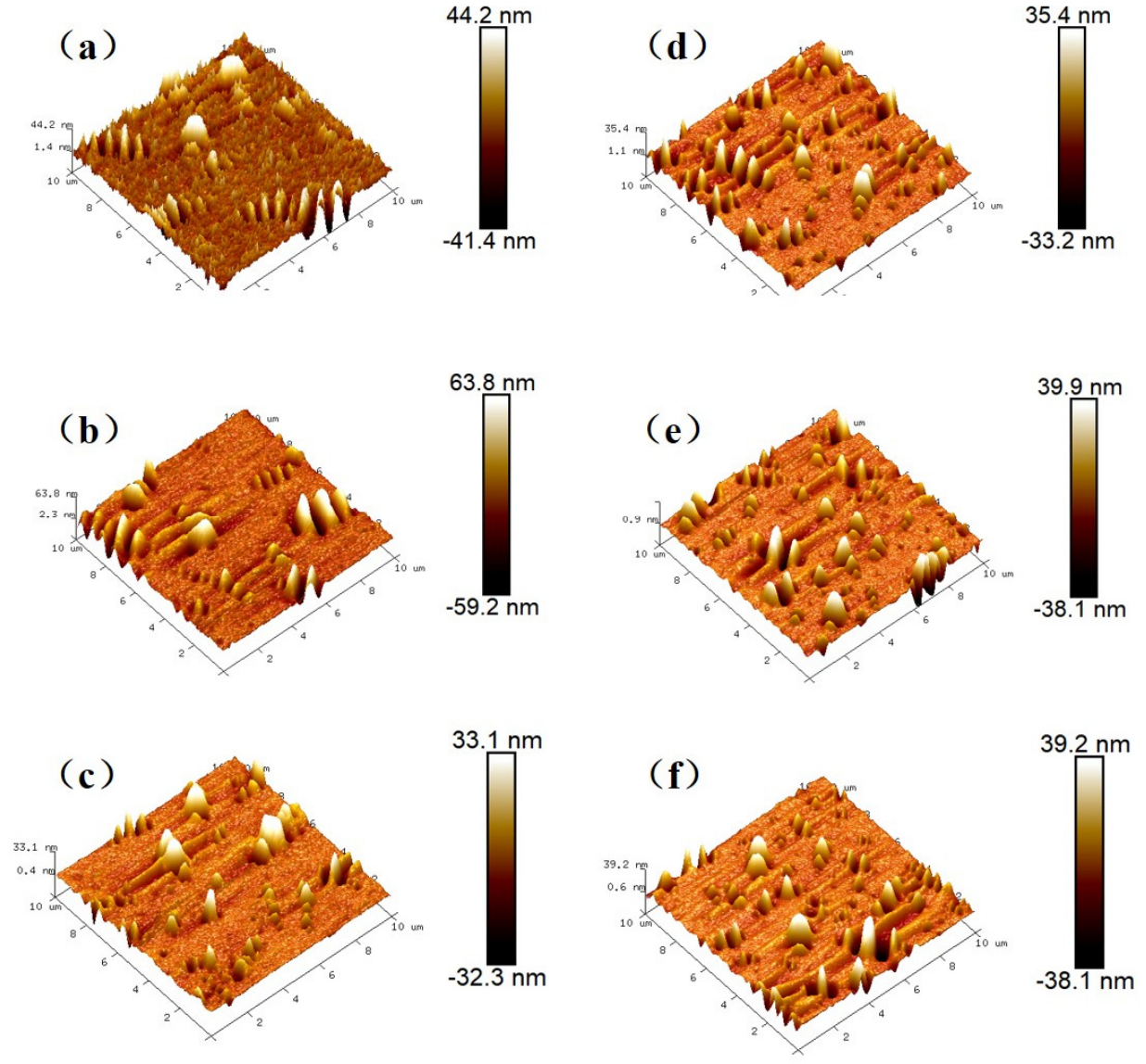

Figure 4. (a) 3D AFM images of base asphalt; (b) base asphalt after RTFOT aging; (c) base asphalt after PAV aging; (d) graphene-modified asphalt; (e) graphene-modified asphalt after RTFOT aging; (f) graphene-modified asphalt after PAV aging. 
Quantitative analysis data including roughness, number peaks found, and minimum and maximum peak depth can be extracted from Figure 4 through "AFM softwareNanoscope Analysis" and the list in Table 1.

Table 1. Basic data parameters extracted from the 3D AFM topographies.

\begin{tabular}{|c|c|c|c|c|}
\hline \multicolumn{3}{|c|}{ Indicators } & \multirow{2}{*}{$\frac{\text { Base Asphalt }}{9.1}$} & \multirow{2}{*}{$\begin{array}{c}\text { Graphene-Modified Asphal } \\
6.5\end{array}$} \\
\hline \multirow{12}{*}{ Aging states } & \multirow{4}{*}{ Unaged } & Roughness (nm) & & \\
\hline & & Number Peaks Found (number) & 141.0 & 137.0 \\
\hline & & Minimum Peak Depth (nm) & 70.5 & 48.4 \\
\hline & & Maximum peak Depth (nm) & 69.2 & 45.3 \\
\hline & \multirow{4}{*}{ RTFOT } & Roughness $\left(R_{\mathrm{q}}\right)$ & 12.0 & 7.5 \\
\hline & & Number Peaks Found (number) & 133.0 & 140.0 \\
\hline & & Minimum Peak Depth (nm) & 77.9 & 67.9 \\
\hline & & Maximum Peak Depth (nm) & 83.1 & 63.9 \\
\hline & \multirow{4}{*}{ PAV } & Roughness $\left(R_{\mathrm{q}}\right)$ & 11.0 & 7.3 \\
\hline & & Number Peaks Found (number) & 130.0 & 137.0 \\
\hline & & Minimum Peak Depth (nm) & 53.3 & 68.3 \\
\hline & & Maximum Peak Depth (nm) & 57.7 & 64.5 \\
\hline
\end{tabular}

Firstly, the variation in the surface morphology can be quantitatively analyzed by the difference between the microscopic phase states of asphalt based on the roughness index (root-mean-square roughness $\left(R_{\mathrm{q}}\right)$, average roughness, and maximum height roughness) [32]. In this study, the relationship between the microscopic phase states and $R_{\mathrm{q}}$ was investigated. $R_{\mathrm{q}}$ was calculated as follows:

$$
\begin{gathered}
R_{\mathrm{q}}=\sqrt{\frac{\iint\left[h(x, y)-h_{0}\right]^{2} d A}{\iint d A}} \\
h_{0}=\frac{\iint h(x, y) d A}{\iint d A}
\end{gathered}
$$

where $A$ is the scanning area, which measured $10 \mu \mathrm{m} \times 10 \mu \mathrm{m}$ in this study; $h(x, y)$ is the height function of the morphology (nm); and $h_{0}$ is the reference height $(\mathrm{nm})$. The $R_{\mathrm{q}}$ of each sample listed in Table 1 was obtained using "AFM software-Nanoscope AnalysisRoughness," and was also presented in forms of graphs, as shown in Figure 5.

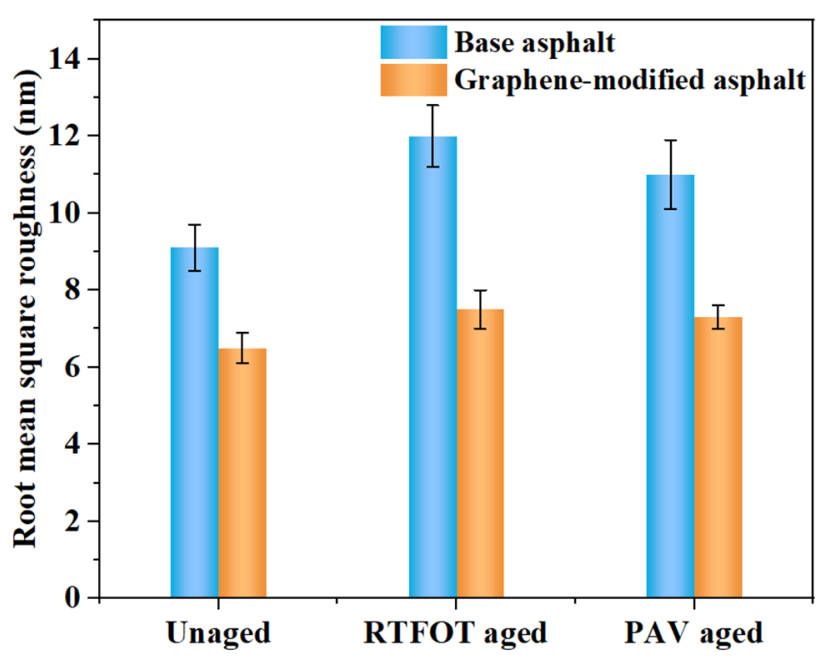

Figure 5. Microscopic surface roughness index of asphalt.

As shown in Figure 5, the $R_{\mathrm{q}}$ of the graphene-modified asphalt was smaller than that of asphalt, indicating that the addition of graphene reduced the roughness of the 
asphalt surface. The surface roughness is related to the self-healing ability and adhesion performance of asphalt [33]. Briefly, the higher the roughness of the asphalt binder, the better the self-healing ability and adhesion performance of the asphalt. The roughness increased after short-term aging, whether in the base asphalt or graphene-modified asphalt $[34,35]$. However, the roughness decreased after long-term aging. The different effects of graphene on the AFM morphology and roughness of asphalt after short- and long-term aging were primarily attributed to the decrease in the light components (saturated hydrocarbon and aromatic hydrocarbon) and, correspondingly, the increase in asphaltene and resin contents [36]. In this case, more asphaltenes were attached to the wax chips during the formation of the "bee structure," resulting in an increase in the "bee structure" volume and the AFM roughness of both the base and graphene-modified asphalt after short-term aging.

It was observed that the $R_{\mathrm{q}}$ of the two types of asphalts increased after RTFOT aging but decreased after PAV aging. This may be because the aging degree of RTFOT was lower, a smaller number of light components were volatilized, and the heavy components were exposed, thereby causing an increase in the surface roughness. Meanwhile, the aging degree of PAV was higher, thereby resulting in a larger number of lightweight elements to be evaporated; consequently, the asphalt transitioned from a multiphase structure to a single-phase structure. The simplification of the phase state reduced the surface roughness. Although the $R_{\mathrm{q}}$ of the two types of asphalts increased after RTFOT aging, the increment in the graphene-modified asphalt was smaller than that of the base asphalt. After PAV aging, the $R_{\mathrm{q}}$ of the two types of asphalts decreased, but the reduction in the graphene-modified asphalt was less than that of the base asphalt. Therefore, it can be inferred from $R_{\mathrm{q}}$ that graphene addition enhanced the anti-aging ability of the base asphalt.

Secondly, the variation in the surface morphology can be quantitatively analyzed by the number of peaks found and peak depth. A group of peaks associate to form a bee structure. The number of bee structures has been previously discussed and here the number of peaks found have not been talked about. A frequency histogram of peak depth distributions is constructed, as presented in Figure 6. As shown, the peak depth distribution histogram of the graphene-modified asphalt under different aging conditions exhibited a smaller peak line than that of the base asphalt, indicating that the number of peaks with greater depth in the graphene-modified asphalt was fewer and the distribution occupied a smaller proportion of the area. The peak heights of the unaged, short-term aged, and long-term aged base asphalt were concentrated in the vicinity of 70,83 , and $62 \mathrm{~nm}$, respectively. The peak heights of the unaged, short-term aged, and long-term aged graphene-modified asphalt were concentrated in the vicinity of 47,60 , and $57 \mathrm{~nm}$, respectively. The addition of graphene might have affected the accumulation of structural components in the "bee structures," thereby reducing the peak height. The height of the after-aged "bee structure" decreased owing to the change in the asphalt components caused by asphalt aging, the decrease in non-polar components (saturated and aromatic), and the increase in polar features (colloids and asphaltenes).

\subsection{Discussion of Asphalt Microstructure Based on Liquid-Solid Phase Transformation Theory}

In our opinion, the formation of "bee structures" and the effect of graphene on the "bee structures" can be elucidated using the basic theory of "liquid-solid phase transition". According to thermodynamic equilibrium theory, a phase transition can occur to form a new phase when the material is cooled to the phase transition temperature. Asphalt, an extremely complex organic mixture, appears in the molten state at high temperatures. During cooling, some components of molten asphalt can undergo liquid-solid phase transition, which results in phase separation in asphalt. The "bee structure" is the result of phase separation in asphalt. According to Gibbs, the phase change process can be categorized into two, i.e., nucleation-growth phase change and continuous phase change. In our opinion, the "bee structure" formation of asphalt belongs to nucleation-growth phase change. Moreover, the phase change process can be categorized into diffusive phase 
change or non-diffusive phase change based on the lattice migration characteristics. In our opinion, the "bee structure" formation of asphalt is a crystallization process that belongs to diffusive phase change. Therefore, the "bee structure" formation and the effect of graphene on the "bee structure" can be briefly analyzed as follows.

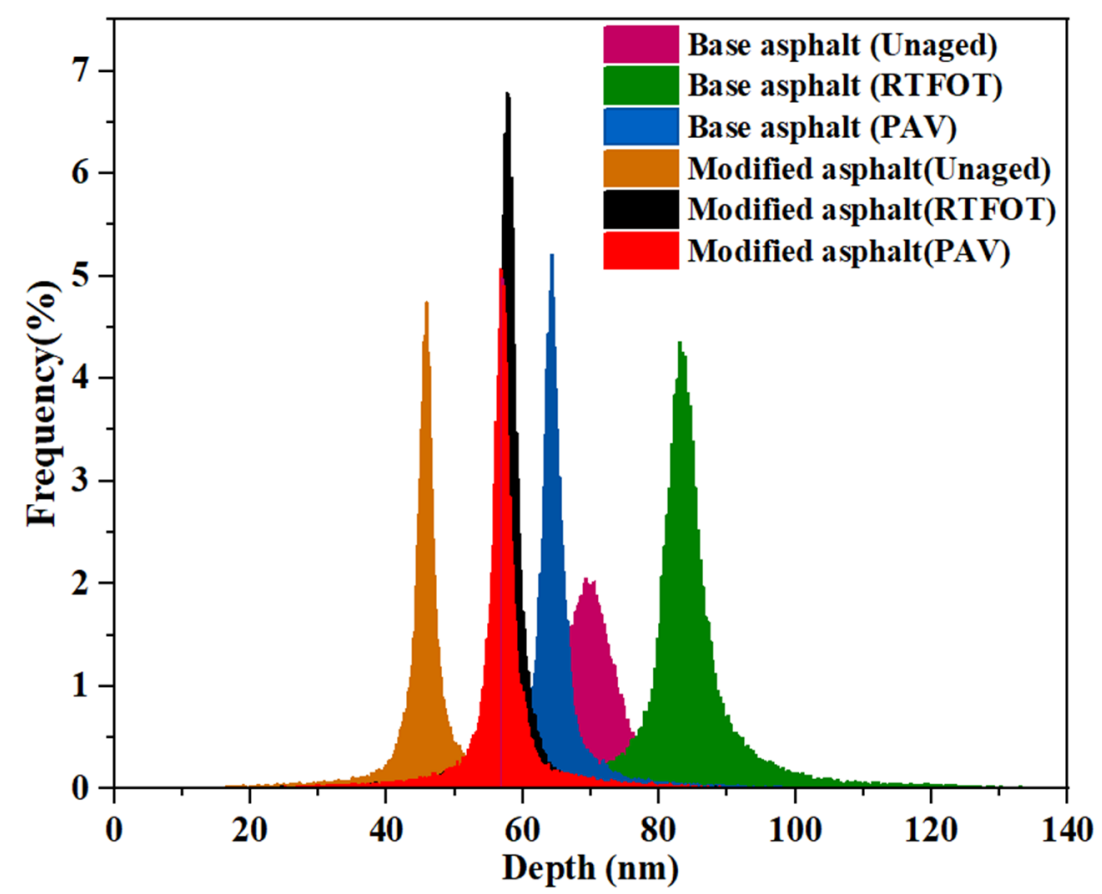

Figure 6. Height distribution of asphalt micromorphology.

\subsubsection{Analysis of "Bee Structure" Formation}

The formation of the "bee structure" has been debated, and in our opinion, the "bee structures" of asphalt are due to wax crystallization or associations involving wax and other concretes (such as asphaltenes and modifiers). During the freezing of asphalt, crude and residue oil-hydrocarbon mixtures with high melting points capable of precipitation via crystallization - are collectively known as wax. Wax is vital to the formation of the "bee structure." The appearance of needle-flake crystals after cooling signifies the presence of microcrystalline wax in asphalt [37].

Wax crystallization involves the transition from a nuclear embryo to a crystal nucleus, followed by a crystal. During cooling, the alkane molecules that were distributed randomly in molten asphalt change from a high free energy state (liquid state) to a low free-energy state (crystalline state), in which the alkane molecules within the short-range are arranged orderly to form nucleus embryos of the "nuclear embryo", which facilitates the further formation of a stable crystal nucleus. A nuclear embryo is a prerequisite for the construction of a nucleus. However, the nuclear embryo will disintegrate if the temperature increases, whereas it will form a stable nucleus that will enlarge and develop crystals if the melt continues to be cooled. The crystallization process comprises nucleation formation and grain growth, both of which require the appropriate supercooling degree. As the temperature decreases, these molecules will undergo a continuous connect-fracture and fracture-connect process to form ordered lattice points until a critical size is attained (a new stable state), i.e., a crystal nucleus [38]. Finally, other surrounding molecules will always cover the crystal lattice points and gradually form a thin slice structure that approaches the crystal nucleus and causes the crystal nucleus to develop into a needle-shaped crystal.

The growth of crystal occurs in the region where the polymerization energy between the crystal and free paraffin is the greatest, resulting in the fastest growth of the sheet structure located on the side of the crystal nucleus. In the other components of the microcrystalline wax and asphalt, asphaltene molecules serve as the core for accumulating crystal 
clusters and then further develop them into "bee structures." When the asphalt system is cooled to below the crystallization temperature, the oil in the asphalt on both sides of the peak sheet will ascend along the peak, which can be considered a capillary phenomenon in molten asphalt [39]. Figure 7 shows a schematic diagram of the precipitation of the "bee structures." In the molten state, asphaltic components (saturates, aromatics, resins, and asphaltenes) are mixed to a homogeneous state. Subsequently, through modification, the graphene modifier is uniformly dispersed in the molten asphalt to form a homogeneous system. During cooling, graphene and asphaltenes will become nucleation sites, and the wax will crystallize easily, thereby resulting in "bee structures."
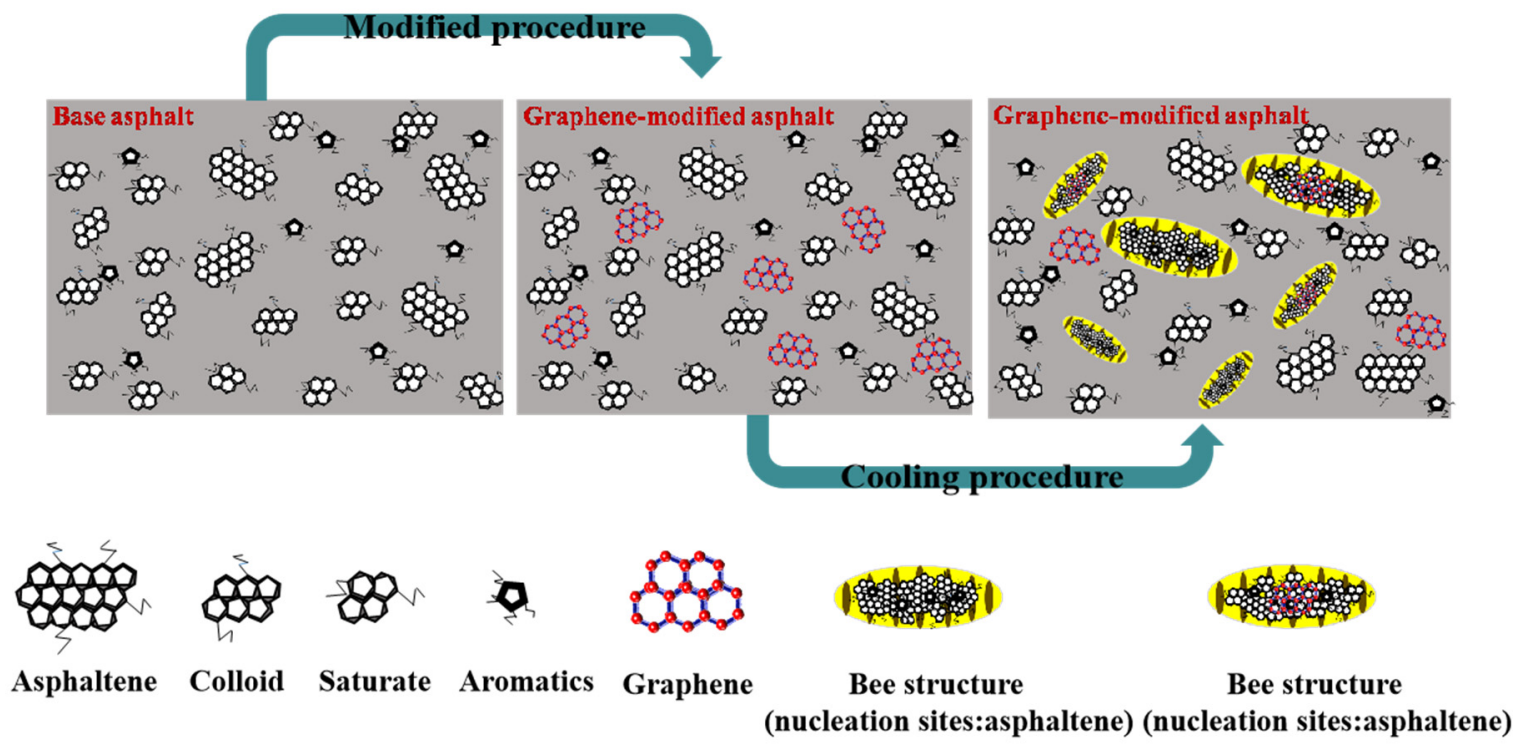

Figure 7. Schematic diagram of precipitation process of "bee structures".

\subsubsection{Effect of Graphene on the Bee Structures of Asphalt}

Previous conclusions indicated that the modified graphene "bee structures" appeared in a greater quantity and were smaller than those of the base asphalt. The formation of a crystal nucleus is the first step in crystallization, and the nucleation process can be categorized into inhomogeneous and homogeneous nucleation based on crystal nucleation theory. Homogeneous nucleation refers to the same probability of nucleus generation in undercooled melts. Meanwhile, inhomogeneous nucleation refers to a formation process facilitated by various catalytic positions such as the surface, interface, cracks, and walls.

The body of the stable graphene modifier will become the catalytic site for nucleus formation in modified asphalt, and this is classified under inhomogeneous nucleation. The incorporation of graphene provides numerous nucleation sites, and interfaces provide regular (spherical) templates on which wax molecules can be deposited [40]. The barrier of inhomogeneous nucleation $\left(\Delta G_{K}{ }^{*}\right)$ is less than that of homogeneous nucleation $\left(\Delta G_{K}\right)$, and the relationship exists in the asphalt, as shown in Equation (3), where $\theta$ represents the contact angle between a cap-shaped nucleus and a flat substrate, as depicted in the classical nucleation theory. Figure 8 shows the cap-shaped model of inhomogeneous nucleation. Cos $\theta$ can be calculated from Young's equation (Equation (4)). In Equation 4, $\gamma_{n l}, \gamma_{s l}$, and $\gamma_{s n}$ refer to the interfacial free energies between the nucleus and liquid, substrate and liquid, and substrate and nucleus, respectively. $f(\theta)$ can be obtained from Equation (5) of the geometric relationship of the cap model, and its value is less than or equal to 1.

$$
\begin{aligned}
& \Delta G_{K}^{*}=\Delta G_{K} f(\theta) \\
& \cos \theta=\frac{\gamma_{s l}-\gamma_{s n}}{\gamma_{n l}}
\end{aligned}
$$




$$
f(\theta)=\frac{(2+\cos \theta)(1-\cos \theta)^{2}}{4} \leq 1
$$

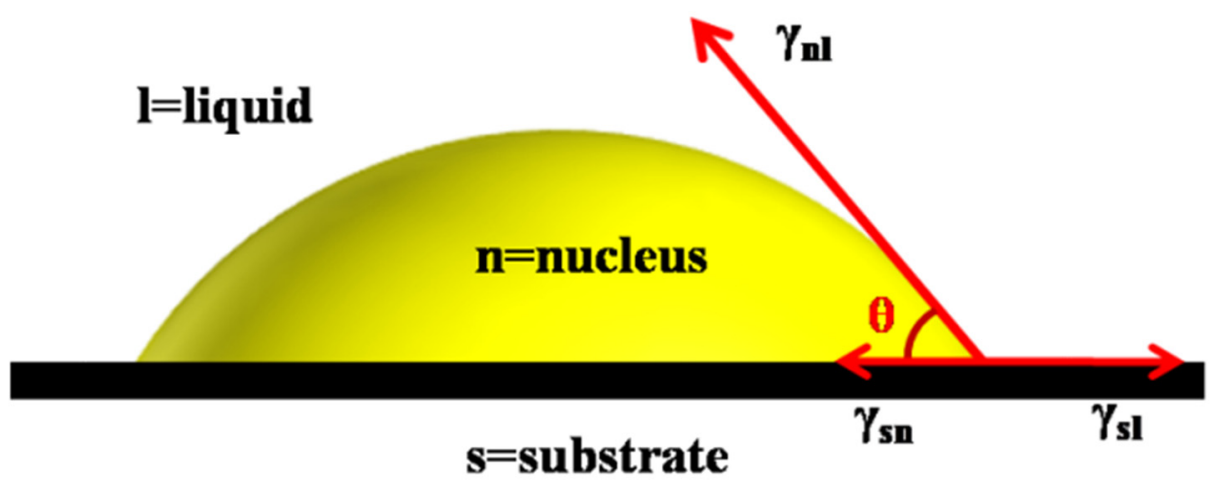

Figure 8. Cap-shaped model of inhomogeneous nucleation.

When the crystal nucleus is formed on the nucleating agent, the nucleation barrier decreases with the contact angle $(\theta)$, and the inhomogeneous nucleation barrier is lower than the homogeneous nucleation barrier, which facilitates crystallization. In the base asphalt, asphaltene can serve as a nucleating agent. By contrast, in the graphene-modified asphalt, uniformly dispersed graphene in asphalt will share its role as a nucleating agent with asphaltene. Although wax can be detached via inhomogeneous nucleation in both the base and modified asphalt, the number of nucleating agent particles in both cases will differ. In our opinion, the graphene modifier can serve as an additional dispersed nucleation center that facilitates the formation of a large number of smaller wax crystals [41]. Therefore, the number of "bee structures" in the graphene-modified asphalt will be higher than that of the base asphalt. Additionally, graphene can result in a lower "bee structure" volume owing primarily to the formation of a relatively compact gel network in the modified asphalt. In our opinion, the formation of the "bee structures" is categorized under diffusive phase transition, and the increased viscosity of modified asphalt hinders the diffusion and transfer of wax molecules.

The growth stage of the "bee structure" can be explained based on diffusion theory. A detailed explanation has been presented in our previous study [27]. In asphalt, a lower viscosity results in less intermolecular interactions, whereas a smaller resistant force toward migration results in a higher molecular migration rate, which facilitates the migration of asphalt components. The viscosity of the base asphalt is less than that of the graphenemodified asphalt. The wax components can migrate quickly in the base asphalt, thereby facilitating the development of the "bee structure." Meanwhile, the number of nucleation sites in the base asphalt is less than that of the graphene-modified asphalt. Therefore, the asphaltic "bee structures" of the base asphalt enlarges, and their distributions are scattered. Meanwhile, the viscosity of the modified asphalt is high, resulting in the low migration speed of the wax molecules. Furthermore, graphene as an asphaltene can serve as a nucleation site and impede particle migration. The factors above can result in the abundant quantity and smaller size of "bee structures" in modified asphalt.

\section{Conclusions}

The micromorphology of unaged and aged base asphalt and graphene-modified asphalt were investigated via AFM. The micrograph variations were compared and analyzed. The formation mechanism of asphaltic "bee structures" and the effect of graphene on the "bee structures" were discussed. The main conclusions obtained are as follows:

(1) Graphene can serve as additional dispersed nucleation centers that facilitate the formation of numerous smaller "bee structures";

(2) The micrograph variation of the graphene-modified asphalt after aging was smaller than that of the base asphalt. Moreover, the $R_{\mathrm{q}}$ of the graphene-modified asphalt with 
different aging degrees was lower than that of the base asphalt, indicating that graphene addition improved anti-aging performance;

(3) The formation of "bee structures" in asphalt can be explained as follows: During the cooling of asphalt, alkanes were arranged to form a nucleus embryo, which then underwent nucleation and growth. Additionally, graphene affected the nucleation and growth processes;

(4) Basic material rules, phase transformation theory, and diffusion theory were introduced to analyze the growth morphology of the "bee structures".

Author Contributions: Conceptualization, X.L. (Xian Li); methodology, X.L. (Xian Li) and X.L. (Xiaocun Liu); software, Q.W. and X.Z.; validation, Y.W. (Yanling Wu) and H.W.; formal analysis, Q.W. and H.S.; investigation, H.W. and L.F.; data curation, X.Z. and L.F.; writing-original draft preparation, X.L. (Xian Li); writing — review and editing, Y.W. (Yanling Wu) and H.S.; visualization, X.L. (Xiaocun Liu); supervision, Y.W. (Yanmin Wang); project administration, Y.W. (Yanmin Wang). All authors have read and agreed to the published version of the manuscript.

Funding: This research received no external funding.

Institutional Review Board Statement: Not applicable.

Informed Consent Statement: Not applicable.

Data Availability Statement: The data is available on the request to the corresponding author.

Acknowledgments: This work was supported by the Applied Basic Research Projects of China's Ministry of Transport (No. 2015319817150), and the Shandong Jiaotong University "Climbing" Research Innovation Team Program.

Conflicts of Interest: The authors declare no conflict of interest.

\section{References}

1. Sun, D.; Yu, F.; Li, L.; Lin, T.; Zhu, X.Y. Effect of chemical composition and structure of asphalt binders on self-healing. Constr. Build. Mater. 2017, 133, 495-501. [CrossRef]

2. Lyne, Å.L.; Wallqvist, V.; Rutland, M.W.; Claesson, P.; Birgisson, B. Surface wrinkling: The phenomenon causing bees in bitumen. J. Mater. Sci. 2013, 48, 6970-6976. [CrossRef]

3. Loeber, L.; Sutton, O.; Morel, J.V.J.M.; Valleton, J.M.; Muller, G. New direct observations of asphalts and asphalt binders by scanning electron microscopy and atomic force microscopy. J. Microsc. 1996, 182, 32-39. [CrossRef]

4. Pauli, A.T.; Grimes, R.W.; Beemer, A.G.; Turner, T.F.; Branthaver, J.F. Morphology of asphalts, asphalt fractions and model wax-doped asphalts studied by atomic force microscopy. Int. J. Pavement Eng. 2011, 12, 291-309. [CrossRef]

5. Jäger, A.; Lackner, R.; Eisenmenger-Sittner, C.; Blab, R. Identification of four material phases in bitumen by atomic force microscopy. Road Mater. Pavement Des. 2004, 5, 9-24. [CrossRef]

6. De Moraes, M.B.; Pereira, R.B.; Simão, R.A.; Leite, L.F.M. High temperature AFM study of CAP 30/45 pen grade bitumen. J. Microsc. 2010, 239, 46-53. [CrossRef]

7. Masson, J.F.; Leblond, V.; Margeson, J. Bitumen morphologies by phase-detection atomic force microscopy. J. Microsc. 2006, 221, 17-29. [CrossRef]

8. Li, R.; Wang, P.; Xue, B.; Pei, J. Experimental study on ageing properties and modification mechanism of Trinidad lake asphalt modified bitumen. Constr. Build. Mater. 2015, 101, 878-883. [CrossRef]

9. Xing, C.; Liu, L.; Li, M. Chemical Composition and ageing Characteristics of Linear SBS Modified Asphalt Binders. Energy Fuels 2020, 34, 4194-4200. [CrossRef]

10. Hung, A.M.; Fini, E.H. AFM study of asphalt binder "bee" structures: Origin, mechanical fracture, topological evolution, and experimental artifacts. RSC Adv. 2015, 5, 96972-96982. [CrossRef]

11. Ji, X.; Hou, Y.; Zou, H.; Chen, B.; Jiang, Y. Study of surface microscopic properties of asphalt based on atomic force microscopy. Constr. Build. Mater. 2020, 242, 118025. [CrossRef]

12. Hung, A.M.; Goodwin, A.; Fini, E.H. Effects of water exposure on bitumen surface microstructure. Constr. Build. Mater. 2017, 135, 682-688. [CrossRef]

13. Ma, Y.; Li, L.; Wang, H.; Wang, W.; Zheng, K. Laboratory Study on Performance Evaluation and Automobile Exhaust Degradation of $\mathrm{Nano}^{-\mathrm{TiO}_{2}}$ Particles-Modified Asphalt Materials. Adv. Mater. Sci. Eng. 2021, 2021, 1-13. [CrossRef]

14. Su, M.; Si, C.; Zhang, Z.; Zhang, H. Molecular dynamics study on influence of Nano-ZnO/SBS on physical properties and molecular structure of asphalt binder. Fuel 2020, 263, 116777. [CrossRef]

15. Yang, L.; Zhou, D.; Kang, Y. Rheological Properties of Graphene Modified Asphalt Binders. Nanomaterials 2020, $10,2197$. [CrossRef] 
16. Qian, G.; Yang, C.; Huang, H.; Gong, X.; Yu, H. Resistance to ultraviolet aging of nano-SiO 2 and rubber powder compound modified asphalt. Materials 2020, 13, 5067. [CrossRef]

17. Ren, Z.; Zhu, Y.; Wu, Q.; Zhu, M.; Guo, F.; Yu, H.; Yu, J. Enhanced storage stability of different polymer modified asphalt binders through nano-montmorillonite modification. Nanomaterials 2020, 10, 641. [CrossRef]

18. Cheraghian, G.; Wistuba, M.P. Effect of Fumed silica nanoparticles on ultraviolet aging resistance of bitumen. Nanomaterials 2021, 11, 454. [CrossRef]

19. Zhang, H.; Gao, Y.; Guo, G.; Zhao, B.; Yu, J. Effects of ZnO particle size on properties of asphalt and asphalt mixture. Constr. Build. Mater. 2018, 159, 578-586. [CrossRef]

20. Wu, S.; Zhao, Z.; Li, Y.; Pang, L.; Amirkhanian, S.; Riara, M. Evaluation of ageing resistance of graphene oxide modified asphalt. Appl. Sci. 2017, 7, 702. [CrossRef]

21. Zeng, W.; Wu, S.; Pang, L.; Sun, Y.; Chen, Z. The utilization of graphene oxide in traditional construction materials: Asphalt. Materials 2017, 10, 48. [CrossRef]

22. Li, Y.; Wu, S.; Amirkhanian, S. Investigation of the graphene oxide and asphalt interaction and its effect on asphalt pavement performance. Constr. Build. Mater. 2018, 165, 572-584. [CrossRef]

23. Liu, K.; Zhang, K.; Shi, X. Performance evaluation and modification mechanism analysis of asphalt binders modified by graphene oxide. Constr. Build. Mater. 2018, 163, 880-889. [CrossRef]

24. Liu, K.; Zhang, K.; Wu, J.; Muhunthan, B.; Shi, X. Evaluation of mechanical performance and modification mechanism of asphalt modified with graphene oxide and warm mix additives. J. Clean. Prod. 2018, 193, 87-96. [CrossRef]

25. Zhu, J.; Zhang, K.; Liu, K.; Shi, X. Adhesion characteristics of graphene oxide modified asphalt unveiled by surface free energy and AFM-scanned micro-morphology. Constr. Build. Mater. 2020, 244, 118404. [CrossRef]

26. Moreno-Navarro, F.; Sol-Sánchez, M.; Gámiz, F.; Rubio-Gámez, M.C. Mechanical and thermal properties of graphene modified asphalt binders. Constr. Build. Mater. 2018, 180, 265-274. [CrossRef]

27. Li, X.; Wang, Y.M.; Wu, Y.L.; Wang, H.R.; Chen, M.; Sun, H.D.; Fan, L. Properties and modification mechanism of asphalt with graphene as modifier. Constr. Build. Mater. 2021, 272, 121919. [CrossRef]

28. Yu, X.; Burnham, N.A.; Tao, M. Surface microstructure of bitumen characterized by atomic force microscopy. Adv. Colloid Interface Sci. 2015, 218, 17-33. [CrossRef]

29. Giessibl, F.J. The qPlus sensor, a powerful core for the atomic force microscope. Rev. Sci. Instrum. 2019, 90, 011101. [CrossRef]

30. Hong, H.; Zhang, H.; Zhang, S. Effect of multi-dimensional nanomaterials on the ageing behavior of asphalt by atomic force microscope. Constr. Build. Mater. 2020, 260, 120389. [CrossRef]

31. Redelius, P.; Soenen, H. Relation between bitumen chemistry and performance. Fuel 2015, 140, 34-43. [CrossRef]

32. Chen, A.; Liu, G.; Zhao, Y.; Li, J.; Pan, Y.; Zhou, J. Research on the aging and rejuvenation mechanisms of asphalt using atomic force microscopy. Constr. Build. Mater. 2018, 167, 177-184. [CrossRef]

33. Wang, M.; Liu, L. Investigation of microscale ageing behavior of asphalt binders using atomic force microscopy. Constr. Build. Mater. 2017, 135, 411-419. [CrossRef]

34. Zhou, X.; Sun, B.; Wu, S.; Zhang, X.; Liu, Q.; Xiao, Y. Evaluation on self-healing mechanism and hydrophobic performance of asphalt modified by siloxane and polyurethane. J. Wuhan Univ. Technol. Sci. Ed. 2019, 34, 630-637. [CrossRef]

35. Ma, W.; Huang, T.; Guo, S.; Yang, C.; Ding, Y.; Hu, C. Atomic force microscope study of the ageing/rejuvenating effect on asphalt morphology and adhesion performance. Constr. Build. Mater. 2019, 205, 642-655. [CrossRef]

36. Xu, M.; Yi, J.; Feng, D.; Huang, Y.; Wang, D. Analysis of adhesive characteristics of asphalt based on atomic force microscopy and molecular dynamics simulation. ACS Appl. Mater. Interfaces 2016, 8, 12393-12403. [CrossRef] [PubMed]

37. Yang, F.; Zhu, H.; Li, C.; Yao, B.; Wang, F.; Chen, J.; Sun, G. Investigation on the mechanism of wax deposition inhibition induced by asphaltenes and wax inhibitors. J. Pet. Sci. Eng. 2021, 204, 108723. [CrossRef]

38. Wang, T. Study on the Wax Crystals' Microscopic Characteristic of Nan Yang Crude Oil; China University of Petroleum: Beijing, China, 2009.

39. Singhal, H.K.; Sahai, G.C.; Pundeer, G.S.; Chandra, K. Designing and selecting wax crystal modifier for optimum field performance based on crude oil composition. In Proceedings of the SPE Annual Technical Conference and Exhibition, Dallas, TX, USA, 6-9 October 1991; Society of Petroleum Engineers: Richardson, TX, USA, 1991. [CrossRef]

40. Yang, F.; Paso, K.; Norrman, J.; Li, C.; Oschmann, H.; Sjöblom, J. Hydrophilic nanoparticles facilitate wax inhibition. Energy Fuels 2015, 29, 1368-1374. [CrossRef]

41. Yang, F.; Zhao, Y.; Sjöblom, J.; Li, C.; Paso, K.G. Polymeric wax inhibitors and pour point depressants for waxy crude oils: A critical review. J. Dispers. Sci. Technol. 2015, 36, 213-225. [CrossRef] 